\title{
Affective psychopathology in Huntington's Disease: the Johns Hopkins hypothesis and German psychiatry ${ }^{1}$
}

No clinician would seriously doubt that patients with Huntington's Disease (HD) consistently suffer from progressive dementia. Most would also agree that those afflicted can sometimes present with clinical pictures closely resembling the 'functional' psychoses. Yet, in most published work, the 'psychotic' phenomena referred to - usually delusions and hallucinations - have mainly been viewed as being 'schizophrenia-like'. Moreover, the literature also reveals strong tendencies towards interpreting much of the psychopathology found in terms of a diagnosis of personality alteration.

On the other hand, only few studies prior to the 1970s have pointed out that prominent affective features might occur in HD (e.g. Davenport, 1916; Bolt, 1970). Since 1975, however, a group of research workers at the Johns Hopkins Hospital has systematically presented a case for the hypothesis that affective syndromes represent the most relevant 'functional' psychopathology to be found in HD and, consequently, should have pride of place in diagnosis (McHugh \& Folstein, 1975; Folstein, 1983; Folstein et al. 1979, 1983a,b). They maintain that this is not only the case during the life-time of many Huntington patients, but also in a significant number of their similarly affected kin. Thus far, the diagnostic discussions in their papers have been exclusively conducted within the context of English-speaking, albeit Kraepelinean, points of view.

The purpose of this editorial, then, is to focus on some clinical concepts that have been utilized in some selected typical German-speaking research on the 'functional' psychopathology associated with HD and contrast these with the Hopkins hypothesis. In so doing, special emphasis will be placed on clarifying the central role played by Panse (1942), whose work on HD, according to Strömgren (1967), has been curiously neglected outside of Germany. Indeed, with respect to his psychopathological views on this illness, these remain scattered in various sections of his monograph, making it not all that easy to extract fully, integrate and interpret them. This is also probably the main reason why Panse's position in this regard is usually only incompletely summarized in non-German-speaking sources (e.g. Slater \& Roth, 1969).

\section{AFFECTIVE CHANGES IN HD}

There can be no doubt that older German-speaking clinicians saw affective changes in patients with Huntington's Disease (HD). For example, Entres (1921) reported that mood changes in HD probands could occur quite often either in the direction of anxiety and fearfulness, whining or weeping, depression, suicidal ideation and suicidal attempts, or in that of hypomanic or manic affectivity. Furthermore, he said that irritability might play a very prominent part in any kind of depressive or manic mood state. However, whereas Entres also stressed that these mood abnormalities could even represent long-term and lasting changes, other important authors during the 1920 s tended to disagree with him.

Thus, writing in Bumke's Handbuch, Runge (1928), although admitting that mood symptoms could frequently appear initially in HD, nonetheless claimed that 'true' depressive states were on the whole a relatively rare event. In his view, moreover, the same was the case with respect to suicidal ideation and attempted suicide. In addition, Runge said that irritability and excitement could often be seen but, paradoxically, he made no explicit mention that elevated mood changes could occur. Another often cited author, Meggendorfer (1923), more or less shared Runge's general clinical

\footnotetext{
1 Address for correspondence: Dr Karl Koehler, Psychiatric University Clinic, Voss Strasse 4, 6900 Heidelberg, West Germany.
} 
opinions. However, in contrast to the latter he pointed out that euphoria and expansiveness could appear not only early but also in much later stages.

In our view, there seems to be no real advantage in reporting in any further detail what many other German writers might have said with regard to affective psychopathology in HD up to - and, indeed, even after - the advent of Panse's (1942) influential monograph. Apparently, he was the only German-speaking author to demonstrate more than an en passant focus on the possibility that affective disorder might be a core psychopathological feature in HD before, however, ultimately rejecting such a hypothesis out of hand. Thus, Panse first carefully cited the views of the American authors Davenport \& Muncey (1916), who had earlier postulated the existence of a manic-depressive subgrouping within the entire universe of HD probands. In his subsequent critique of their views, he began by categorically and globally stating that any depressive and euphoric mood elements by chance present in HD could 'clearly be differentiated' from those found in so-called 'endogenous' states.

Panse, thereupon, more specifically claimed that euphoric excitements in HD were not at all 'essentially' of similar quality to those seen in 'endogenous' mania because the former presented with a 'massive organic colouring', or when not so clearly 'organic' usually manifested a kind of 'silly hebephrenic' aspect, akin to that found in so-called maniform schizophrenia. Given this bias, expansive psychotic phenomena were then easily and understandably interpreted by Panse as being 'schizophrenia-like'; moreover, he even felt that on more careful inspection their 'organic' nature or quality could often be ascertained. Indeed, this method of 'explaining away' an elevated mood change and its associated features can be found repeatedly in his case vignettes.

However, when depressive mood changes in HD probands, especially initially, were at issue, Panse was forced to concede that the clinical differentiation from manic-depressive depression at times could be cross-sectionally particularly difficult. Nonetheless, he confidently continued to stress that some of the depressive features seen in HD - as was also the case with the manic ones - were actually 'essentially' distinct from that part of so-called manic-depressive illness. In his view, depressive states occurring in HD were mainly only of a transient nature and often only reflections of 'moroseness' instead of a 'true' or 'endogenous' kind of mood change. It is no wonder, then, that the mood disturbance in HD, which was also described by Panse as being 'acutely labile', was basically interpreted in terms of impulsivity. Moreover, he stressed finding no evidence for what he called the 'periodic' occurrence of depressive states of this kind, although he mentioned that a decided tendency existed for HD probands to present with repeated 'acute dysphoric attacks'.

And yet, even if Panse was unwilling to size up the depressive or dysphoric features he found in HD in terms of a 'true' manic-depressive depression-like syndrome, he could hardly gainsay their great clinical relevance. Thus, he strongly emphasized the point that such states were often closely linked with suicidal attempts or completed suicides. Nonetheless, as was the case with his interpretation of the elevated mood changes seen in HD, Panse once more tried to 'explain away' the depressive affect elicited. For example, since his HD patients frequently manifested what he termed a lack of drive and energy (Laschheit), sometimes coupled with a psychopathological colouring reflecting affective flattening (Versandung), heconcluded that any super-imposed depressivedysphoric elements could not really be 'essentially' the same as the symptomatology of 'true' manic-depressive depression.

\section{PERSONALITY CHANGE IN HD}

Thus far, the point has been made that the mood changes as well as some other associated symptoms more or less arbitrarily called affective criteria - for example, in DSM-III - when seen by Germanspeaking psychiatrists in HD probands, especially in the early stages of illness, for various reasons were not considered 'essentially' identical to those found in 'true' or 'endogenous' affective disorder. Immediately, the question arises: how then did they tend to interpret such features clinically? The most plausible answer is: almost always in diagnostic terms of a change of personality, provided that psychotic features were absent. In this connection, Kehrer's hybrid term 
'Choreopathie', coined in 1928, no doubt played a not unimportant role in fostering this bias. His concept of choreopathy covered not only so-called morbid personality changes occurring during the initial stages of HD, but also any pre-morbid abnormal personality characteristics that may have always - for example, from childhood or puberty on - been present in many HD patients.

Later, Panse (1942) accepted Kehrer's concept of choreopathy. Yet, at the same time, he also clearly narrowed its extent considerably. Basically, he mainly spoke of choreopathy in those HD probands in whom so-called personality alterations occurred before - perhaps even many years before - any neurological features had appeared. In contrast to Kehrer, however, he did not apply the concept in instances in which any habitual personality abnormalities might have always, from the earliest age on, been present in those manifesting HD much later. Moreover, he did not use the term to cover similar personality disturbances when found in the relatives of HD probands.

In any event, Panse's very extensive description and interpretation of the personality abnormalities that could occur in HD patients only reinforces our contention that he failed to consider the diagnosis of an affective syndrome to be a serious possibility, although, paradoxically, affective psychopathology was clinically at the very heart of his choreopathy concept. For example, he emphasized that the affective state of $\mathrm{HD}$ probands with personality alteration most often manifested itself in a change in the direction of moroseness and irritability - indeed, he stated that this might even be long-lived - or in that of 'organic' euphoria; finally, he concluded that it was on such a psychopathological basis that serious acute affective lability, impulsivity, and aggressiveness frequently arose.

Panse reported that only about $20 \%$ of his HD cases presented with choreopathy as he defined it. Finding that Schneider's (1950) breakdown of psychopathy was really not so useful to him, since clear-cut psychopathic types were rather rare in his sample, he relied on his own ad hoc classification. Thus, he placed about $19 \%$ of all his HD probands into what he called a 'callous-instinctual-irritable' grouping, whereas the remaining $1 \%$ of choreopathic patients were grouped into a rag-bag category more or less covering those with either some hyperthymic, depressive, anxious, fantastic, hysterical or asthenic features. Moreover, his HD patients demonstrating criminal behaviour or/and alcohol abuse were almost without exception to be found among his choreopaths.

Probably because of Panse's work, choreopathy has remained a very popular concept, one with a great suggestive power, in German psychiatry. Indeed, it probably represented the main reason why almost all the initial non-psychotic 'functional' psychopathology found in HD was usually interpreted as being indicative of organically caused personality alteration. For example, so influential a modern Schneiderian as Huber (1981) continues to define the content of the term in Panse's classical clinical sense: 'the initial pseudo-psychopathic changes (are composed of) characterological and affective abnormalities, acute mood changes in the direction of moroseness and depression, sudden aggressive behaviour, irritability... or euphoric unconcern'.

However, although Huber shares Panse's bias with respect to interpreting any affective features in HD probands in terms of personality alteration, glaring discrepancies between the two with regard to the amount and kind of so-called psychopathic changes found are nonetheless obvious. This suggests that the choreopathy concept might have been radically widening since the Second World War. Thus, only about $20 \%$ of Panse's HD probands were classified as being choreopathic, but this was the case in $81 \%$ of Huber's patients. Moreover, whereas the asthenic type was only one of the many found in Panse's $1 \%$ 'mixed' choreopathic grouping, Huber categorized $31 \%$ of HD probands in terms of an organic neurasthenic psychopathy; however, the remaining $50 \%$ of patients demonstrating so-called choreopathic changes in his sample were not divided any further. As was the case with Panse's choreopathy, Huber's concept of neurasthenic psychopathy also includes many of those features which, in the face of a depressive mood change, could certainly be interpreted in terms of the other associated behavioural or/and experiential affective symptoms utilized as criteria for DSM-III major depression and dysthymic disorder - for example, complaints about poor concentration, being slowed down, irritability and tiredness. 


\section{DISCUSSION}

In German psychiatry, argument has often raged on the question of whether or not so-called 'endogenous' manic and depressive syndromes could occur when relevant exogenous disturbances of the brain were present. For example, Bonhoeffer (1909) admitted having seen manic pictures in organic states, yet remained sceptical as to whether they really had any relationship to 'true' manic-depressive disorder. With respect to states of 'endogenous' origin presenting with the symptomatology of the depressive phase of a manic-depressive psychosis, he felt that these were extremely rare; indeed, he claimed never to have come across one which he could categorize as such with certainty. Later, Schneider $(1932 a, b)$, although acknowledging that various 'generally unspecific' somatically caused depressive and manic symptoms and syndromes might appear, nonetheless repeatedly and categorically insisted that these were clearly distinguishable from and had nothing to do with the mood changes occurring in his concept of depressive and manic types of cyclothymia, the latter being a much more narrow concept of affective illness than Kraepelin's very wide manic-depressive illness.

Seen in this light, the clinical bias against eliciting manic-depressive syndromes or cyclothymic states in HD probands manifested by most German research workers of today or yesteryear easily becomes understandable. The tendency to 'explain away' all prominent affectivity that might point towards what we now would call a full or partial DSM-III affective syndrome probably not only led them not to probe much further in this diagnostic direction, but also to tend to interpret any such affectivity when found and without psychotic features in terms of personality alteration which they liked to label as choreopathic. Indeed, clinically they seem to have been particularly impressed by any aggressive or/and irritable tendencies appearing in HD probands, which most likely tempted them much more towards this interpretation.

In contrast, the Hopkins Group, although undoubtedly also eliciting much clinically obvious aggressiveness and irritability - the $24 \%$ of all cases diagnosed in one of their reports with intermittent explosive disorder clearly attests to this (Folstein, 1983)-presumably enquires further in all cases presenting with features of a similar kind for purposes of determining whether a full or partial syndrome in DSM-III terms is present behind this kind of psychopathology. As a corollary to the points just made: whereas for the German psychiatrists even mood-congruent psychotic features in HD usually constituted grounds enough to set them thinking of a "schizophrenialike' state, regardless of the affective features, even mood-incongruent psychotic symptoms in most instances would not upset the conviction of an affective syndrome by the Hopkins clinicians.

Summing up, then, in terms of a simplistic slogan: German research workers, on the one hand, have always mainly focused on disturbances of moroseness/moodiness in HD, which they used to diagnose personality change; the Hopkins investigators, on the other, most likely interpret many of the same features as being part of the mood and mood-related symptoms pointing towards DSM-III affective illness. In these circumstances, that they tend to find more of what they preferred to seek comes as no surprise.

\section{KARL KOEHLER AND HENNING SASS}

We wish to thank Dr Susan Folstein of the Johns Hopkins University for her kind help in clarifying some unclear points in the Hopkins concept of affective disorder in the context of HD research on the occasion of a recent visit by one of the authors (K.K.) to Baltimore.

\section{REFERENCES}

Bolt, J. M. (1970). Huntington's Chorea in the west of Scotland. British Journal of Psychiatry 116, 259-270.

Bonhoeffer, K. (1909). Zur Frage der endogenen Psychosen. Zentralblatt für Nervenheilkunde 32, 499-505.

Davenport, C. B. (1916). Huntington's Chorea in relation to heredity and eugenics. American Journal of Insanity 73, 195-222.
Davenport, C. B. \& Muncey, E. B. (1916). Huntington's chorea in relation to heredity and eugenics. Bulletin of Eugenics Record Office 17. Carnegie Institute: Washington, D.C.

Entres, J. L. (1921). Zur Klinik und Vererbung der Huntingtonschen Chorea. Monographien aus dem Gesamtgebiete der Neurologie und Psychiatrie, Vol. 27. Springer: Berlin.

Folstein, S. E. (1983). Progress Report. Summary of Program for the Ascertainment and Assessment for Huntington's Disease for the 
Period 1 July 1982 to 30 June 1983. Johns Hopkins Hospital: Baltimore.

Folstein, S. E., Folstein, M. F. \& McHugh, P. R. (1979). Psychiatric syndromes in Huntington's Disease. In Advances in Neurology, Vol. 23 (ed. T. N. Chase, N. S. Wexler and A. Barbeau), pp. 281-289. Raven Press: New York.

Folstein, S. E., Abbott, M. H., Chase, G. A., Jensen, B. A. \& Folstein, M. F. (1983a). The association of affective disorder with Huntington's Disease in a case series and in families. Psychological Medicine 13, 537-542.

Folstein, S. E., Franz, M. L., Jensen, B. A., Chase, G. A. \& Folstein, M. F. (1983b). Conduct disorder and affective disorder among offspring of patients with Huntington's Disease. Psychological Medicine 13, 45-52.

Huber, G. (1981). Psychiatrie (3rd edn). Schattauer: St uttgart/New York.

Kehrer, F. (1928). Erblichkeit und Nervenleiden. I. Ursachen und Erblichkeitskreis von Chorea, Myoklonie und Athetose. Monographien aus dem Gesamtgebiete der Neurologie und Psychiatrie, Vol. 50. Springer: Berlin.

McHugh, P. R. \& Folstein, M. F. (1975). Psychiatric syndromes of Huntington's chorea: A clinical and phenomenologic study. In Psychiatric Aspects of Neurologic Disease (ed. D. F. Benson and D. Blumer), pp. 267-286. Grune \& Stratton: New York.
Meggendorfer, F. (1923). Die psychischen Störungen bei der Huntingtonschen Chorea, klinische und genealogische Untersuch. ungen. Zeitschrift für die gesamte Neurologie und Psychiatrie 87, $1-49$.

Panse, F. (1942). Die Erbchorea. Eine klinisch-genetische Studie. Thieme: Leipzig.

Runge, W. (1928). Psychosen bei Hirnerkrankungen. In Handbuch der Geisteskrankheiten, Vol. 3: Die exogenen Reaktionsformen und die organischen Psychosen (ed. O. Bumke), pp. 634-646. Springer: Berlin.

Schneider, K. (1932a). Uber Abgrenzung und Seltenheit des sogenannten manisch-depressiven Irreseins. Münchner medizinische Wochenschrift 39, 1549-1552.

Schneider, K. (1932b). Probleme der klinischen Psychiatrie. Thieme: Leipzig.

Schneider, K.(1950). Diepsychopathischen Persönlichkeiten. Deuticke: Vienna.

Slater, E. \& Roth, M. (1969). Clinical Psychiatry. Williams \& Wilkins: Baltimore.

Strömgren, E. (1967). Psychiatrische Genetik. In Psychiatrie der Gegenwart, Vol. 1: Grundlagenforschung zur Psychiatrie Part A (ed. H.W. Gruhle, R. Jung, W. Mayer-Gross and M. Müller), pp. 1-69. Springer: Berlin-Heidelberg-New York. 